\title{
Article \\ Women Do Not Utilise Family Planning According to Their Needs in Southern Malawi: A Cross-Sectional Survey
}

\author{
Maria Lisa Odland ${ }^{1,2, *(D)}$, Oda Vallner ${ }^{2}$, Marlen Toch-Marquardt ${ }^{2}$ and Elisabeth Darj ${ }^{2,3}$ \\ 1 Institute of Applied Health Research, Birmingham University, Birmingham B15 2TT, UK \\ 2 Department of Public Health and Nursing, NTNU, Norwegian University of Science and Technology, \\ 7491 Trondheim, Norway; oda.vallner@gmail.com (O.V.); marlen.toch@ntnu.no (M.T.-M.); \\ elisabeth.darj@ntnu.no (E.D.) \\ 3 Department of Obstetrics and Gynaecology, St Olavs Hospital, 7030 Trondheim, Norway \\ * Correspondence: m.l.odland@bham.ac.uk
}

Citation: Odland, M.L.; Vallner, O.; Toch-Marquardt, M.; Darj, E. Women Do Not Utilise Family Planning According to Their Needs in Southern Malawi: A Cross-Sectional Survey. Int. J. Environ. Res. Public Health 2021, 18, 4072. https://doi.org/10.3390/ ijerph18084072

Academic Editor: Paul Tchounwou

Received: 28 February 2021

Accepted: 9 April 2021

Published: 13 April 2021

Publisher's Note: MDPI stays neutral with regard to jurisdictional claims in published maps and institutional affiliations.

Copyright: (c) 2021 by the authors. Licensee MDPI, Basel, Switzerland This article is an open access article distributed under the terms and conditions of the Creative Commons Attribution (CC BY) license (https:// creativecommons.org/licenses/by/ $4.0 /)$

\begin{abstract}
Malawi is a low-income country with a high maternal mortality rate. This study aimed to investigate the use of contraception and factors associated with unmet need of family planning among fertile women in selected health facilities in southern Malawi. A cross-sectional study design was employed using a validated questionnaire to investigate the unmet need. A total of 419 pregnant women, who attended antenatal clinics at a central hospital and two district hospitals, voluntarily participated in the study. Logistic regression analysis was used to identify possible factors associated with unmet needs. Amongst the participants, 15.1\% reported unmet need, 27.0\% had never used a contraceptive method, and $27.2 \%$ had an unwanted pregnancy. Being married, 20-24 years of age, living in a rural area, and high parity were protective factors against having unmet need regarding family planning. Malawi, a country with a young population and a high fertility rate, has a high level of unmet family planning need. Barriers and facilitators need to be identified and addressed at different levels by the health care system, society, and the government of Malawi.
\end{abstract}

Keywords: family planning; unmet need; contraception; Malawi

\section{Introduction}

Maternal mortality is still a big problem globally, but especially in low-income countries. Malawi is a low-income country with a population of 18 million [1]. The country has a fertility rate of 4.4 [2] and a maternal mortality ratio (MMR) of 439 per 100,000 women, which is among the highest in the world [2]. About 6-30\% of all maternal deaths in Malawi are estimated to be caused by unsafe abortions [3], and an estimated $54 \%$ of pregnancies in Malawi were unintended in 2013 [4]. According to the restrictive abortion law, termination of pregnancy is only legal in order to save a pregnant woman's life [5]. Still, 140,000 induced abortions were estimated in the country in 2015, and considering the illegality of abortions, the majority were most likely unsafe [6]. Legalizing abortions has led to a decrease in maternal mortality in other countries [7], and liberalising the abortion law in Malawi has been discussed for years, but so far no change has happened. Whilst we are waiting for the abortion law to change, other efforts to reduce maternal mortality need to be undertaken. In a report by the Guttmacher Institute from 2014, it was estimated that if all unmet family planning needs were met for women in Malawi, unintended births and unsafe abortions would drop by $87 \%$ and maternal mortality would decline by more than $40 \%$ [4].

One way to reduce the MMR could by improving access to family planning. A systematic review regarding the usage of contraceptives in Sub-Saharan Africa found major barriers preventing the uptake of family planning services, such as cultural and societal pressure on women, socioeconomic status, financial barriers, and lack of access to services [8]. An Ugandan study points to barriers leading to reduced access to contraceptives 
as misconceptions, gender power relations, socio-cultural expectations, judgmental health services, lack of privacy, and confidentiality as public health concerns that are possibly associated with mortality among women attributed to low contraceptive use [9]. Consequently, identifying the barriers and facilitators to family planning is important. An unmet need of family planning (unmet need) is defined as the proportion of women who want to stop or delay childbearing but who are not using any method of contraception [10]. In the Demographic and Health Survey (DHS) from 2015-2016, the unmet need was estimated to be $18.7 \%$ among married women and $39.8 \%$ for sexually active unmarried women [2]. An assessment by the WHO, Ipas, and the Malawian Ministry of Health in 2011 summarized four key recommendations to reduce the MMR; strengthening the national family planning programme; addressing the sexual and reproductive health needs of young Malawians; reviewing restrictive abortion laws; and strengthening post abortion care services [3]. Thus, family planning is recognized as an important factor to achieve a reduction in unwanted pregnancies, early motherhood, and unsafe abortions (consequently reducing maternal mortality). In order to increase access to family planning and reduce unmet need, barriers in access to family planning need to be determined before they can be addressed. This study aimed to investigate the prevalence of the unmet need among a selected group of fertile women in southern Malawi and possible factors associated with unmet need within this group.

\section{Materials and Methods}

\subsection{Study Design, Setting, and Participants}

We used a cross-sectional survey design to investigate the unmet need of contraceptives among women in Malawi. The study was conducted at the Queen Elizabeth Central Hospital (QECH) in Blantyre, and at the district hospitals of Chikwawa and Chiradzulu. We aimed to include as many women of reproductive age as possible during the study period of five weeks. A convenience sampling method was used to target pregnant women aged 16 to 49 years attending the antenatal clinic (ANC) at the selected health facilities. All women attending the ANCs were invited for voluntary participation.

A validated, 18 question questionnaire, based on "Questions and Filters for unmet need Definition" from the WHO, was used in the data collection [11]. We added 11 questions to describe sociodemographic characteristics. The questionnaire was available in English and a translated version in Chichewa. The nurse in charge informed the women about the study in Chichewa and of their right to decline to participate without this affecting their treatment at the antenatal clinic. The nurses who administrated the questionnaires were also available to read the questionnaire for the participants if necessary. There were also posters with information about the study at each ANC. The women who agreed to participate received a questionnaire and could answer it in private whilst waiting for their antenatal check-ups. Informed consent forms were signed by the participants, or with thumb print if illiterate. The participants did not receive any compensation for completing the questionnaire, but were offered refreshments whilst completing the form.

\subsection{Description of Variables}

The dependent variable unmet need was constructed from three different parts: (1) women who did not want to get pregnant and did not use anything to avoid pregnancy; (2) women who wanted to have another child later, but would not use anything to space pregnancies; and (3) women who did not want any more children and would not use anything to limit childbearing.

Age was categorized into five-year groups (16-19, 20-24, 25-29, 30-34, and $\geq 35)$, area of living was divided into urban (Blantyre) or rural (Chikwawa or Chiradzulu), achieved level of education in three categories (low = primary school, middle $=$ secondary school, and high = higher education), and marital status was married or non-married (single, widowed, separated, or cohabiting). 


\subsection{Analyses}

Data from the questionnaires were entered manually into a statistical software package SPSS 20.0. Descriptive statistics were computed for all variables used in the analysis. Logistic regression analysis was used to calculate odds ratios (ORs) and 95\% confidence intervals (CIs) to identify possible factors associated with unmet need. We calculated one model including area of living (Model I) and a second model adjusting for possible confounding factors (Model II).

\section{Results}

\subsection{Descriptive Results}

The number of women visiting the ANCs at the approached three health facilities amounted on average to 420 every week, and the response rate was $40 \%$. During four weeks in October-November 2017, 419 women were included in the study. Most women were aged 25-29 years and almost everyone was married (92.1\%). The average number of children was 1.5 child (range $0-8$ ) per woman and $33.7 \%$ were pregnant with their first child (Table 1).

Table 1. Characteristics of pregnant women $(n=419)$ attending antenatal clinics at three hospitals in southern Malawi.

\begin{tabular}{|c|c|c|c|c|c|}
\hline & \multirow{2}{*}{\multicolumn{2}{|c|}{ Total }} & \multicolumn{3}{|c|}{ Living Area $^{4}$} \\
\hline & & & $\begin{array}{c}\text { Blantyre } \\
n=144\end{array}$ & $\begin{array}{c}\text { Chikwawa } \\
n=109\end{array}$ & $\begin{array}{c}\text { Chiradzulu } \\
n=157\end{array}$ \\
\hline & $n$ & $\%$ & $\%$ & $\%$ & $\%$ \\
\hline \multicolumn{6}{|l|}{ Unmet Need $^{1}$} \\
\hline Yes & 62 & 15.1 & 20.1 & 7.3 & 15.1 \\
\hline No & 348 & 84.9 & 79.9 & 92.7 & 84.9 \\
\hline \multicolumn{6}{|l|}{ Age $^{2}$} \\
\hline $16-19$ & 63 & 15 & 4.9 & 18.3 & 22.9 \\
\hline $20-24$ & 108 & 25.8 & 13.3 & 31.2 & 33.8 \\
\hline $25-29$ & 110 & 26.3 & 33.6 & 22.9 & 22.9 \\
\hline $30-34$ & 87 & 20.8 & 37.1 & 12.8 & 11.5 \\
\hline $35+$ & 49 & 11.7 & 11.2 & 14.7 & 8.9 \\
\hline \multicolumn{6}{|l|}{ Education } \\
\hline Low & 156 & 37.2 & 7.6 & 60.6 & 49 \\
\hline Middle & 187 & 44.6 & 46.5 & 35.8 & 48.4 \\
\hline High & 76 & 18.1 & 45.8 & 3.7 & 2.5 \\
\hline \multicolumn{6}{|l|}{ Marital status } \\
\hline Married & 386 & 92.1 & 93.8 & 92.7 & 90.4 \\
\hline Unmarried & 33 & 7.9 & 6.3 & 7.3 & 9.6 \\
\hline \multicolumn{6}{|l|}{ Parity $^{3}$} \\
\hline 0 & 141 & 33.7 & 25.0 & 39.4 & 33.9 \\
\hline 1 & 94 & 22.4 & 23.6 & 16.5 & 22.2 \\
\hline 2 & 99 & 23.6 & 34.0 & 16.5 & 23.7 \\
\hline $3+$ & 82 & 19.6 & 17.4 & 27.5 & 20.2 \\
\hline
\end{tabular}

The total unmet need in our study was $15.1 \%$ and the age group 20-24 years had the lowest odds of unmet need. Women attending the antenatal clinic at the QECH in Blantyre had a higher unmet need (20.1\%). These women were also older and had higher educational levels. In the district areas the unmet need was lower; Chiradzulu (15.1\%) and Chikwawa (7.3\%) (Table 1). 
As indicated in Table 2, 27.0\% of the included women had never used contraceptives, and $85 \%$ of these women wished that they had been able access to contraception. The women who used contraceptives normally received them from a hospital or from clinics in rural areas. The most frequently used contraceptives were injections (58.2\%) and implants $(26.5 \%)$. Few women had access to IUDs (3.6\%), or emergency contraception $(2.0 \%)$ after unprotected intercourse. A substantial proportion of respondents $(45.0 \%)$ reported side effects of their contraceptives, with bleeding disturbance being the most common side effect $(43.5 \%)$ (Table 2$)$.

Table 2. Contraceptive use among pregnant women $(n=419)$ at three hospitals in southern Malawi.

\begin{tabular}{|c|c|c|}
\hline Contraceptive Use & (n) & $(\%)$ \\
\hline Use of any method & 306 & 73.0 \\
\hline Never used & 113 & 27.0 \\
\hline Wish for use, if not using & 96 & 85 \\
\hline \multicolumn{3}{|l|}{ Modern methods } \\
\hline Injection & 178 & 58.2 \\
\hline Implant & 81 & 26.5 \\
\hline Pill & 52 & 17.0 \\
\hline Male condom & 51 & 17.0 \\
\hline IUD & 11 & 3.6 \\
\hline ECP & 6 & 2.0 \\
\hline Other & 3 & 1 \\
\hline \multicolumn{3}{|l|}{ Traditional } \\
\hline Rhythm and withdrawal & 21 & 6.9 \\
\hline Side Effects & 138 & 45.0 \\
\hline Bleeding disturbance & 60 & 43.5 \\
\hline Loss of period & 8 & 5.8 \\
\hline Long-lasting effect & 3 & 2.2 \\
\hline Gastrointestinal & 18 & 13.0 \\
\hline Headache & 11 & 8.0 \\
\hline Backache & 7 & 5.1 \\
\hline General pain & 7 & 5.1 \\
\hline Heart palpitations & 5 & 3.6 \\
\hline Hypertension & 5 & 3.6 \\
\hline Other ${ }^{1}$ & 17 & 12.3 \\
\hline \multicolumn{3}{|l|}{ Place of receipt } \\
\hline Hospital & 107 & 35.0 \\
\hline Clinic & 23 & 7.5 \\
\hline Private clinic & 16 & 5.0 \\
\hline Private hospital & 2 & 0.7 \\
\hline Health centre & 7 & 2.0 \\
\hline CHW & 3 & 1.0 \\
\hline Family members & 1 & 0.3 \\
\hline Pharmacy & 1 & 0.3 \\
\hline Shop & 7 & 2.0 \\
\hline
\end{tabular}

$\overline{\mathrm{IUD}}=$ intrauterine device, $\mathrm{CHW}=$ community health workers, ECP $=$ emergency contraceptive pills. ${ }^{1}$ Other includes: dizziness, dyspareunia, loss of libido, tiredness, increased appetite, dysmenorrhea, vaginismus, increased vaginal discharge, hormonal change, mental change, and oedemas.

Close to a third of the women $(27.2 \%)$ did not want or did not plan their current pregnancy. However, $65.0 \%$ wanted another child, but the current pregnancy was mistimed, and $78.4 \%$ wished to be able to space the interval between pregnancies by at least two years. The most frequent choices the women considered for spacing pregnancies were injections $(46.4 \%)$ or implants $(26.3 \%)$ (Table 3$)$. 
Table 3. Family planning among pregnant women $(n=419)$ at three hospitals in southern Malawi.

\begin{tabular}{|c|c|c|}
\hline Family Planning & Total $(n)$ & Total $(\%)$ \\
\hline Wanted pregnancy & 304 & 72.6 \\
\hline Unwanted pregnancy & 114 & 27.2 \\
\hline Mistimed & 55 & 48.0 \\
\hline Wanted to stop childbearing & 22 & 19.0 \\
\hline \multicolumn{3}{|l|}{ Desire for another child } \\
\hline Want more children & 276 & 65.0 \\
\hline Not sure & 43 & 10.3 \\
\hline \multicolumn{3}{|l|}{ When } \\
\hline Within two years & 8 & 2.5 \\
\hline Wait at least two years & 250 & 78.4 \\
\hline Don't know when & 49 & 15.4 \\
\hline $\begin{array}{l}\text { Use of any method to space } \\
\text { pregnancy (yes and maybe) }\end{array}$ & 297 & 90.0 \\
\hline Rhythm and withdrawal & 10 & 3.4 \\
\hline Condom & 15 & 5.1 \\
\hline Pill & 14 & 4.7 \\
\hline Implant & 78 & 26.3 \\
\hline IUD & 15 & 5.1 \\
\hline Injection & 138 & 46.5 \\
\hline Don't know & 26 & 8.8 \\
\hline Other ${ }^{1}$ & 1 & 0.3 \\
\hline No desire for more children & 98 & 23.4 \\
\hline $\begin{array}{c}\text { Any method to stop } \\
\text { childbearing (yes and maybe) }\end{array}$ & 85 & 86.7 \\
\hline Rhythm and withdrawal & 1 & 1.2 \\
\hline Condom & 3 & 3.5 \\
\hline Pill & 1 & 1.2 \\
\hline Implant & 11 & 12.9 \\
\hline IUD & 11 & 12.9 \\
\hline Vaginal rings & 4 & 4.7 \\
\hline Injection & 12 & 14.1 \\
\hline $\begin{array}{c}\text { Sterilization (bilateral tubal } \\
\text { ligation) }\end{array}$ & 40 & 47.1 \\
\hline Don't know & 3 & 3.5 \\
\hline Other & 2 & 2.4 \\
\hline
\end{tabular}

${ }^{1}$ Includes emergency contraceptive pill.

Only sixteen women did not want to use contraceptives for spacing or preventing a pregnancy. This was due to various reasons, such as, the husband opposed the use of contraceptives, experiences of side effects, inconvenience, lack of access, or the belief that the occurrence of pregnancy is decided by God.

\subsection{Logistic Regression Analysis}

Women living in the district of Chikwawa had a statistically significantly lower OR, 0.30 (95\% CI 0.13-0.68), of unmet need compared to women living in Blantyre (Table 4). Moreover, women in the age group 20-24 had the lowest OR, 0.29 (95\% CI 0.12-0.71), for unmet need compared to other age groups. Education was not associated with unmet need. Married women had a lower OR of unmet need than unmarried women, and the odds of having unmet need decreased with increasing parity (Table 4). 
Table 4. Logistic regression analyses for the unmet need of family planning in three hospitals in southern Malawi.

\begin{tabular}{|c|c|c|c|c|}
\hline & \multirow{2}{*}{$\begin{array}{c}\text { Model I } \\
\text { OR }\end{array}$} & \multicolumn{3}{|c|}{ Model II ${ }^{2}$} \\
\hline & & CI $(95 \%)$ & OR & CI $(95 \%)$ \\
\hline \multicolumn{5}{|l|}{ Area } \\
\hline Blantyre (RG) ${ }^{1}$ & 1 & & 1 & \\
\hline Chikwawa & 0.30 & $(0.13-0.68)$ & 0.22 & $(0.08-0.65)$ \\
\hline Chiradzulu & 0.72 & $(0.40-1.28)$ & 0.54 & $(0.23-1.23)$ \\
\hline \multicolumn{5}{|l|}{ Age } \\
\hline 16-19 (RG) & & & 1 & \\
\hline $20-24$ & & & 0.29 & $(0.12-0.71)$ \\
\hline $25-29$ & & & 0.41 & (0.14-1.19) \\
\hline $30-34$ & & & 1.05 & $(0.29-3.73)$ \\
\hline$\geq 35$ & & & 2.61 & $(0.56-12.20)$ \\
\hline \multicolumn{5}{|l|}{ Education } \\
\hline High (RG) & & & 1 & \\
\hline Medium & & & 1.27 & $(0.41-3.94)$ \\
\hline Low & & & 1.28 & $(0.55-3.01)$ \\
\hline \multicolumn{5}{|l|}{ Marital Status } \\
\hline $\begin{array}{l}\text { Not married } \\
\quad(R G)\end{array}$ & & & 1 & \\
\hline Married & & & 0.43 & $(0.18-1.04)$ \\
\hline \multicolumn{5}{|l|}{ Parity } \\
\hline 0 births (RG) & & & 1 & \\
\hline 1 & & & 0.32 & $(0.13-0.79)$ \\
\hline 2 & & & 0.23 & $(0.08-0.63)$ \\
\hline $3 \leq$ & & & 0.05 & $(0.01-0.23)$ \\
\hline-2 loglikelihood & \multicolumn{2}{|c|}{351.772} & \multicolumn{2}{|c|}{$303.939^{2}$} \\
\hline
\end{tabular}

\section{Discussion}

In this study we found that three quarters of the included Malawian women have used contraceptives, but $15.1 \%$ reported a current unmet need. Almost a third of the participants had an unwanted pregnancy.

Malawi has a young population, with an average age of 17.2 years in 2015 [12]. The median age at marriage is 17.8 years in the southern parts of Malawi and women have high fertility [2]. The annual population growth in Malawi was 2.6\% in 2018 [1,2]. However, worldwide the estimation of population growth is currently decreasing, and the overall number of women who have access and are using contraceptives is growing [13]. In a Guttmacher report from 2016, in which DHS surveys were conducted in 52 developing countries where, between $8 \%$ and $38 \%$ of married women aged $15-49$ years reported an unmet need of contraception [14]. They wanted to avoid a pregnancy but did not use any method to prevent a new pregnancy [14]. Our estimate of unmet need is somewhat lower than that reported by previous studies from Malawi [2,15]. In the Malawian DHS the unmet need was $20 \%$, and $54 \%$ of pregnancies were estimated to be unintended among married women [2]. This difference in results may indicate that the situation in Malawi is improving and more women are having access to family planning. We would have expected a higher level of unmet need in the Malawi female population, since we included also unmarried women, which is a factor associated with an unmet need [2]. However, another factor that is important to consider is that we asked women at the ANCs. While some of these women had unwanted pregnancies they cannot be considered a representative sample of 
the fertile population, which could have influenced the results. To include women treated for incomplete abortions or a random sample of the population may have revealed higher unmet need. While there may be a trend towards improvement in Malawi, the unmet need we found in our study was still high and needs to be addressed further.

Unmet need tends to be higher among women with a lower educational level, living in rural areas, or those who have a low income, compared to women who are more educated and living in urban areas [14]. However, this partly contradicts our study where we found that women living in the urban area were more likely to have unmet need. Women in Blantyre have better access to schools and universities, and they ought to have better access to contraceptives. In Lao DPR adolescents living in rural districts had lower sexual and reproductive health knowledge compared to urban district residents [16]. One explanation of our findings might be that the urban women have more knowledge regarding family planning, but they do not perceive that they have access to the contraceptives they need. As expected, being younger, unmarried, and having lower education were factors associated with unmet need in our study. Unmet need may lead to teenage pregnancies, girls dropping out of school, early marriages, and loss of opportunities [17].

The age group 20-24 years had the lowest odds of unmet need, and reasons for this may be that women in this age group often are newly married and want to start families. The literacy rate among women in Malawi is about $55 \%$ [18]. The young generation with current access to schools, and thus better education, may become more informed about contraception and methods of family planning. The Ministry of Health in 2001 stated an aim to address the sexual and reproductive health needs of young Malawians [2,4]. Simultaneously, we found that the youngest (16-20 years) and the highest age groups $(\geq 35)$ had higher odds of unmet need. The teenagers living in rural areas also often have lower educational levels, as presented in the Malawi DHS [2].

Other studies have named further reasons for the high risk of unmet need among unmarried women in addition to age and education such as infrequent sex, and the shame associated with asking for, or buying, contraceptives whilst not married [14]. A qualitative study from Kenya showed that women were scared of being seen as promiscuous when using contraceptives [19].

Unplanned or unwanted pregnancies occur due to a number of reasons, such as lack of knowledge, accessibility, availability, affordability, contraceptive failure, and poverty [20]. The challenges that women face to access safe childbirth, also known as the "Three Delay Model" by Thaddeus and Maine, in seeking, reaching, and receiving care, can also be applied for women's access to safe contraception [21]. A woman has to have the knowledge of why, what, and where contraceptives are available. Additionally, she needs money and transportation to such a facility, and to get access to available and affordable contraceptives with few side effects. To use prescribed modern contraceptives, women need financial assets and require medical supervision [22]. In countries with easy access to contraceptives the number of abortions is generally low [23]. In Malawi, where abortion laws are very restrictive, the amount of incomplete abortions is high, probably as a consequence of unsafe and dangerous abortions due to unwanted pregnancies. Hence, the lack of access to safe family planning methods leads to unwanted pregnancies, unsafe abortions, and maternal deaths, is one of the reasons Malawi has one of the highest MMRs in the world [3,24].

Six out of ten women in our study reported that they had used injectable contraceptives, but still there were many barriers in access to family planning. Some women also revealed that their partners opposed the use of contraceptives. How males influence the use of contraceptives has been described in other studies [19,25]. Male opposition was attributed to limited understanding and male dominance in a South African study [26]. Men are often seen as the decision makers in families and influence women's choice of using or not using contraceptives for spacing pregnancies or stopping childbearing [19,26]. Hence, men play an important role when considering unmet need, and men's attitudes and practices need to be considered in future interventions. A Kenyan study showed that barriers to the use of contraceptives were associated with misconceptions of promiscuity 
and fear of side effects or infertility [19]. Almost half of the women in our study who did not use any contraceptives reported side-effects and that contraceptives interfere with bodily processes. Women who used injections and implants reported irregular menstruation, which is a well-known and common side-effect [27]. Additionally, the injection should be administered every three months, which could present a barrier to uptake. A study from Kenya described that women had good knowledge of modern contraceptives, however, this was not necessarily translated into use [19]. Thus, information and counselling are important in the effort to reduce the unmet need and to improve the uptake of more effective methods of contraception, with the ultimate aim to improve reproductive health and maternal mortality [20].

The unmet need and the high fertility rate, together with the identified barriers, need to be addressed at different levels in society. One way is to adhere and implement the recommendations from the Ministry of Health. The aim is to strengthen the family planning programme through education and counselling of sexual and reproductive health, reducing the unmet need of young Malawians, and strengthening the important post abortion care services. It will also be critical to review the country's restrictive abortion laws, a process already ongoing in other African countries [28,29].

We collected data from more than 400 women in a short period, from three hospitals of various sizes, and from urban and rural areas. Additionally, we included unmarried women in contrast to the other reports [2]. There may be some selection bias, as women who agreed to participate are likely to understand and speak English and have a higher level of education. In order to reduce selection bias, we offered a research assistant to read the questionnaire in Chichewa out loud and tick the boxes according to the woman's answers. In the validated WHO questionnaire, no questions were included regarding the ability to cover the cost of contraceptives, and it would have been interesting to explore this as a potential barrier. The descriptive results from our study cannot be generalised to all fertile women in Malawi. To access a group of women at childbearing age, we chose to approach women who made their regular antenatal check-up at three ANCs. We are aware that we did not reach a representative population of all fertile women, including those who are not pregnant, those who are pregnant but not attending any antenatal care, and women admitted to hospitals due to on-going complications of miscarriages or abortions. Including women with on-going incomplete abortions could have given a more complete picture of the unmet need in Malawi. However, we found it unethical to approach women with on-going abortions with questions regarding their unmet need.

We did not include men in our survey, as it was conducted at an antenatal clinic where men are not usually present, and we consider this as a limitation. Men play an important role and may influence women's choice of using contraceptives or not. The International Conference on Reproductive Health, Mumbai (India), arranged by UNFPA/WHO/World Bank, stated already in 1998 that men and women shall have "the same rights to decide freely and responsibly on the number and spacing of their children, and to have access to the information, education and means to enable them to exercise these rights" [30].

\section{Conclusions}

Our results show that there is still high unmet need among women at reproductive age in Malawi. Unmet need was more pronounced among teenagers (16-20 years) and older women ( $\geq 35$ years), unmarried women, and women living in urban areas. The high fertility rate in combination with unmet need should be addressed by Malawian politicians and policymakers in order to improve women's lives and empower women to make their own decisions about their future. Reducing unmet need will ultimately reduce unsafe abortions and subsequently maternal mortality, as per the requirements of the UN Sustainable Developing Goals for all countries. 
Author Contributions: O.V., M.L.O., and E.D. planned and designed the study. O.V. did the data collection, with assistance from M.L.O. M.L.O. wrote the first draft of the manuscript. O.V., M.L.O., M.T.-M., and E.D. contributed to analysis and interpretation of the data. M.T.-M. and O.V. did the statistical analyses. M.L.O. and E.D. gave scientific advice and inputs during the writing process. All authors have read and agreed to the published version of the manuscript.

Funding: This research was funded by the Programme for Global Health and Vaccination Research (GLOBVAC), project number 244672, in conjunction with the Research Council of Norway, and by the Norwegian University of Science and Technology.

Institutional Review Board Statement: The study was conducted according to the guidelines of the Declaration of Helsinki, and ethical approval was given by the Regional Ethics Committee in Mid-Norway (REC 2017/311), and from the College of Medicine Research and Ethics Committee (COMREC P.08/17/2253) in Malawi.

Informed Consent Statement: Written informed consent was given before participation.

Data Availability Statement: The data is not publicly available, but can be made available by request.

Acknowledgments: We would like to thank the research assistants and the participants in this study for their collaboration and participation.

Conflicts of Interest: The authors declare no conflict of interest.

\section{References}

1. The World Bank. Country Profile Malawi, 2018; The World Bank: Columbia, DC, USA, 2018.

2. National Statistics Office. Malawi Demographic and Health Survey 2015-2016, Zomba, Malawi, 2016; The World Bank: Columbia, DC, USA, 2016.

3. Jackson, E.; Johnson, B.R.; Gebreselassie, H.; Kangaude, G.D.; Mhango, C. A strategic assessment of unsafe abortion in Malawi. Reprod. Health Matters 2011, 19, 133-143. [CrossRef]

4. Vlassoff, M.; Tsoka, M. Benefits of Meeting the Contraceptive Needs of Malawian Women. Issues Brief (Alan Guttmacher Inst.) 2014, 2, 1-8.

5. Blackhall's Laws of Malawi, Malawi Penal Code (1930). Available online: www.malawilaws.com (accessed on 1 February 2021).

6. Polis, C.B.; Mhango, C.; Philbin, J.; Chimwaza, W.; Chipeta, E.; Msusa, A. Incidence of induced abortion in Malawi, 2015. PLoS ONE 2017, 12, e0173639. [CrossRef] [PubMed]

7. Latt, S.M.; Milner, A.; Kavanagh, A. Abortion laws reform may reduce maternal mortality: An ecological study in 162 countries. BMC Women's Health 2019, 19, 1. [CrossRef] [PubMed]

8. Haider, T.L.; Sharma, M. Barriers to Family Planning and Contraception Uptake in Sub-Saharan Africa: A Systematic Review. Int. Q. Community Health Educ. 2013, 33, 403-413. [CrossRef] [PubMed]

9. Nalwadda, G.; Mirembe, F.; Byamugisha, J.; Faxelid, E. Persistent high fertility in Uganda: Young people recount obstacles and enabling factors to use of contraceptives. BMC Public Health 2010, 10, 530. [CrossRef]

10. World Health Organisation. Unmet Need for Family Planning. 2015. Available online: https://www.who.int/reproductivehealth/ topics/family_planning/unmet_need_fp/en/ (accessed on 1 February 2021).

11. Questions and Filters for Unmet Need Definition Appendix. Available online: https://dhsprogram.com/topics/upload/ Questions-and-Filters-for-Unmet-Need-Definition-Appendix-A.pdf (accessed on 20 August 2017).

12. Roser, M. U.S. Life Expectancy 1950-2021. Available online: https://www.macrotrends.net/countries/USA/united-states/lifeexpectancy (accessed on 1 February 2021).

13. United Nations. World Fertility and Family Planning 2020; United Nations: New York, NY, USA, 2020.

14. Sedgh, G.; Ashford, L.S.; Hussain, R. Reasons for Unmet Need For Contraception in Developing Countries. N. Y. Guttmacher Inst. 2016, 2, 2015-2016.

15. UN Population Division. Contraceptive Use by Method, 2019; United Nations: New York, NY, USA, 2019.

16. Phongluxa, K.; Langeslag, G.; Jat, T.R.; Kounnavong, S.; Khan, M.A.; Essink, D.R. Factors influencing sexual and reproductive health among adolescents in Lao PDR. Glob. Health Action 2020, 13, 1791426. [CrossRef]

17. Rosenberg, M.; Pettifor, A.; Miller, W.C.; Thirumurthy, H.; Emch, M.A.; Afolabi, S.; Kahn, K.; Collinson, M.; Tollman, S. Relationship between school dropout and teen pregnancy among rural South African young women. Int. J. Epidemiol. 2015, 44, 928-936. [CrossRef]

18. UNESCO. Malawi, 2018; UNESCO: Paris, France, 2018.

19. Ochako, R.; Mbondo, M.; Aloo, S.; Kaimenyi, S.; Thompson, R.; Temmerman, M.; Kays, M. Barriers to modern contraceptive methods uptake among young women in Kenya: A qualitative study. BMC Public Health 2015, 15, 118. [CrossRef]

20. Sedgh, G.; Hussain, R. Reasons for Contraceptive Nonuse among Women Having Unmet Need for Contraception in Developing Countries. Stud. Fam. Plan. 2014, 45, 151-169. [CrossRef] [PubMed]

21. Thaddeus, S.; Maine, D. Too far to walk: Maternal mortality in context. Soc. Sci. Med. 1994, 38, 1091-1110. [CrossRef] 
22. Torres, A.; Forrest, J.D. The costs of contraception. Fam. Plan. Perspect. 1983, 15, 70-72. [CrossRef]

23. Ketting, E.; Visser, A.P. Contraception in the Netherlands: The low abortion rate explained. Patient Educ. Couns. 1994, 23, 161-171. [CrossRef]

24. Levandowski, B.A.; Kalilani-Phiri, L.; Kachale, F.; Awah, P.; Kangaude, G.; Mhango, C. Investigating social consequences of unwanted pregnancy and unsafe abortion in Malawi: The role of stigma. Int. J. Gynecol. Obstet. 2012, 118, S167-S171. [CrossRef]

25. Randrianasolo, B.; Swezey, T.; Van Damme, K.; Khan, M.R.; Ravelomanana, N.; Rabenja, N.L.; Raharinivo, M.; Bell, A.J.; Jamieson, D.; Behets, F.; et al. Barriers to the Use of Modern Contraceptives and Implications for Woman-Controlled Prevention of Sexually Transmitted Infections in Madagascar. J. Biosoc. Sci. 2008, 40, 879-893. [CrossRef] [PubMed]

26. Kriel, Y.; Milford, C.; Cordero, J.; Suleman, F.; Beksinska, M.; Steyn, P.; Smit, J.A. Male partner influence on family planning and contraceptive use: Perspectives from community members and healthcare providers in KwaZulu-Natal, South Africa. Reprod. Health 2019, 16, 89. [CrossRef] [PubMed]

27. Harel, Z.; Biro, F.M.; Kollar, L.M.; Rauh, J.L. Adolescents' reasons for and experience after discontinuation of the long-acting contraceptives depo-provera and norplant. J. Adolesc. Health 1996, 19, 118-123. [CrossRef]

28. Favier, M.; Greenberg, J.M.; Stevens, M. Safe abortion in South Africa: “We have wonderful laws but we don't have people to implement those laws". Int. J. Gynaecol. Obstet. 2018, 143, 38-44. [CrossRef]

29. Blystad, A.; Haukanes, H.; Tadele, G.; Haaland, M.E.S.; Sambaiga, R.; Zulu, J.M.; Moland, K.M. The access paradox: Abortion law, policy and practice in Ethiopia, Tanzania and Zambia. Int. J. Equity Health 2019, 18, 126. [CrossRef]

30. Shalev, C. Rights to Sexual and Reproductive Health-the ICPD and the Convention on the Elimination of All Forms of Discrimination Against Women. Health Hum. Rights 2000, 4, 38-66. [CrossRef] [PubMed] 